\title{
The Information System Management and Its Infrastructure for Supply Chain Management as Antecedents of Financial Performance
}

\author{
Saqib MUNEER ${ }^{1}$
}

Received: October 15, 2019 Revised: November 01, 2019

Accepted: November 15, 2019

\begin{abstract}
A model is presented in this paper to provide understanding of the supply chain integration and supply chain information practices' impact on the manufacturing industries. The supply chain information practices play a crucial role in sharing information between the members of SC network. Thus, it is important to develop a comprehensive understanding of the differences and similarities among ISI and information management. It will allow firms to systematically evaluate and carefully choose the information strategy. The empirical findings of this research offer essential and interesting insights about what role SCI, supply chain information and Supply chain ISI play in determining Malaysia's financial performance. The theoretical gaps addressed in this study are of significant importance, since a little empirical evidence is available regarding system infrastructure and supply chain information management's effectiveness. This research provides further paths of exploring system infrastructure and information management, thereby defining the manufacturing industries' next step in SCM struggle i.e. modifying total integrated SC principle in other manufacturing firms. The Resource-based theory discovered organizational resources as an essential organizational success ingredient. Therefore, in order to recognize its potential value, internal resources, for instance, information system and management must be fully utilized.
\end{abstract}

Keywords : Information System, Supply Chain, Financial Performance, Integration, Infrastructure

JEL Classification Code : O32, O47, P47, C83, M11, M15

\section{Introduction}

In today's competitive business environment, limited product lifestyle and rapid market fluctuations, firms incorporate supply chain networking as a key efficiency and effectiveness indicator. Information sharing is a prerequisite for network and supply chain cooperation (Ramanathan, Subramanian, \& Gunasekaran, 2018). The supply chain network's efficient functioning is dependent upon how the information supply chain functions as a supplementary and complementary force. It explains the crucial role of information at all manufacturing stages, including all

\footnotetext{
1 First Author and Corresponding Author, Assistant Professor, Department of Economics and Finance, College of Business Administration, University of Hail, Saudi Arabia. [Postal Address: 9703 Almuntaza Algharbi, Unit 3, 3390-55424, Hail, Kingdom of Saudi Arabia] Email: saqibmuneer85@gmail.com or sa.muneer@uoh.edu.sa

(c) Copyright: Korean Distribution Science Association (KODISA)

This is an Open Access article distributed under the terms of the Creative Commons Attribution Non-Commercial License (http://Creativecommons.org/licenses/by-nc/4.0/) which permits unrestricted noncommercial use, distribution, and reproduction in any medium, provided the original work is properly cited.
}

activities and processes of production and supply chain. Such information utilization and exchange are equally important for all procurers, suppliers, and integrated business parties (Walker, 2016).Therefore, all information should be effectively transmitted and received by the involved parties, to ensure strong management and smooth information flow and to continuously enhance the manufacturing supply chain's productivity at every stage. Furthermore, the late $21^{\text {st }}$ century has witnessed revolutionary growth in the information technology management and information system infrastructure networks In addition, extensive pressure has been applied by fourth industrial revolution on the manufacturing supply chain to stay updated with the IT and IS trends for maintaining competitiveness (Mukiibi, 2018). Therefore, an efficient downstream and upstream network integration must be ensured by organization within their business relationships (Mukiibi, 2018). It has been highlighted in a study(Salmela $\&$ Huiskonen, 2019) that how various businesses have gained huge information related to technological management, based on their scope, speed and cost. The 
information systems may facilitate in enhancing networks and supply chains visibility, through which appropriate IT innovations can be adopted and integrated, resulting in the improvement of supply chain and network processes.

Information technology provides rapid and continuous changes in industrial business environment by affecting the firm's information sharing ability, therefore, further research is required regarding the impact of IT practices on performance and inter and intra-organizational relationship (Basheer, Siam, Awn, \& Hassan, 2019). Several prior researches have suggested that IT investments generally bring greater productivity, increased performance (Yu, Xiong, \& Cao, 2015)and increased innovation. Whereas, it has also been indicated in other studies that sustained performance benefits cannot be achieved through IT, which consequently results in poor revenue generation ( $\mathrm{Lu}$ et al., 2019). In addition, a study by Jagani, Wallace, and Kunnathur (2016) exhibited that applying interorganizational system of information sharing through IT does not necessarily bring better performance.

Thus, review of earlier researches has revealed that more research is merited concerning performance and information technology (Basheer et al., 2019). Such as, a literature gap has been identified while reviewing the literature, i.e. impact of supply chain information on the performance and practices. Also, some irregularities were also found in the relationship results of performance and supply chain information practices, which indicate that a variable may have been left unnoticed (Yu et al., 2015). Besides, a few studies are also available in the literature which attempted to investigate the role of supply chain integration as a mediator in the relationship of supply chain information practices and firm performance. The existing set of literature also provides the evidence concerning how performance and SC information practices relationship is mediated by supply chain integration (SCI)(Basheer, Hafeez, Hassan, \& Haroon, 2018). Furthermore, the Resource-based theory (RBT) by Barney, industrial organization perspective by Bain and market-led perspective by Porter provide comprehensive explanation regarding how SCI's mediating effect can bring better organizational performance (Hameed, Nawaz, Basheer, \& Waseem, 2019; Sigalas \& Papadakis, 2018). Therefore, the present research is expected to narrow the existing gap in present as well as prior empirical research.

\section{Literature Review}

\subsection{Supply Chain Information Management}

Bahrin, Abdul Munir, and Zolait (2018) defined Supply chain management as the integration of business processes through those suppliers which offer products, information, and services to the end users, thereby adding value to the stakeholders and customers. Therefore, the raw material transformation starts from original state of raw materials and ends at the product completion, which requires a range of firms. The effectiveness of supply chain management heavily depends upon the coordination of flows and integration of business processes within and between firms, through an information system. Kembro, Näslund, and Olhager (2017) suggested that the sharing and optimal chain-wide performance are largely dependent upon information sharing to develop compact integration, which is promoted by the developments in SCIM (Kembro et al., 2017). Moreover, the business processes brought in value by efficiently managing the information throughout the SC. Such value is acquired when information exchange enables the decision making and actions among systems and people. The aim of information management is to develop an optimal services implementation which is needed within the supply chains. Information management is essential since it contributes in new projects acquisition through sharing relevant information, thereby enabling better decisionmaking by firms. These decisions can be negative, positive, inspired or incompetent, but are greatly driven by the acquired information (Walker, 2016).

\subsection{Supply Chain Information System Infrastructure (ISI)}

Generally, the Information technology is incorporated to improve boundary spanning, cross-functional, and the function specific performance (Andoh-Baidoo, 2016). The practitioners have reported that no significant impact of IT has found on the performance timing which calls for the need to introduce an integrated concurrent method, aiming to minimize cycle time. Thus, ISI was introduced to cater this need, which is a new construct covering hardware and software that are used for getting rid of the embedded waste existing within a SC. In a supply chain network, ISI has made it easier to communicate, make interfaces, carry out processes and manage among partnering firms, resulting in the improvement of logistics lead time reduction. This has been achieved by removing firm delays, such as minimizing slack time by incorporating electronic data exchange, automatic data capture and automated material handling, and eradicating bottlenecks. Thus, the Information system infrastructure greatly affects the supply chain by supplying the functional support that is required by the information supply chain.

The SC network's efficiency and range can be improved by providing that infrastructure which could efficiently accelerate the data interchange across the components of various SCs. Moreover, the information system's intrinsic features enable the key manufacturers to not only meet current demands but also anticipate customers' demands for future purposes. In addition, ISI also plans to integrate information flow mechanism for monitoring and developing a coordination within a SC (Gorane \& Kant, 2017). Furthermore, the literature on agility, reengineering business processes, supply chain management and lean 
manufacturing explains the ISI's significance in affecting the SC's performance timing(Bendoly \& Chao, 2016; Thatte \& Agrawal, 2017).

\subsection{Theoretical Framework and Hypothesis Development}

The present study is based on two theoretical frameworks, namely system theory and RBT. Such theories increase the overall strength of information supply chain model. Resource-based theory (RBT) particularly focuses on the internal resource utilization for creating those advantages that are not easier to imitate (Messina, Barros, \& Lucas, 2018). Therefore, firms are required to put more emphasis on process enhancement and information resources for distinctive services and products delivery. It particularly allows SC firms to develop core competencies and competitive advantage for meeting organizational goals and objectives (Paul, Parthasarathy, \& Gupta, 2017). On the other hand, the system theory states that 'in a system all elements work collectively and the interdependent and interrelated parts work in collaboration for carrying out a particular function to meet the system objectives'.

According to Ceric (2016), integration and collaboration of total system makes system theory a suitable framework for the resource-based theory. Putting differently, the present research considers SC as an individual organization whereas, supply chain information practices as the internal resources, that may enhance supply chain integration by efficiently and effectively exchanging information as a single entity, throughout the supply chain. Therefore, integrating supply chain information practices by firms may enhance system integration which then improve performance. Thus, the present study suggests that a relationship exists among supply chain ISI, supply chain information management, financial performance and supply chain integration. The current research considers integration and supply chain perspectives as the theoretical diversion points, thereby emphasizing information's role in system structure and management. Survey questionnaires obtained from reviewing the literature provides the methodological framework for obtaining empirical and contextual information. Other studies from different industries also provide understanding of the described model. In addition, the theoretical framework forms the basis for focusing and interpreting the observations (Walker, 2016).

The data was collected for supply chain ISI, supply chain integration, and supply chain information management for analyzing particular issues concerning performance of manufacturing industries. Supply chain information management contributes to the manufacturing industry by disseminating information between the supply chain members. Within the supply chain systems, the information flow can be easily created in the presence of supply chain integration, with compatible IS and communication infrastructure (Govindana, \& Soleimanib, 2017). Besides, the integration also develops a continuous connection between the SC members through timely and accurate information management, resulting in the increase in manufacturing industries performance. This perspective claims that it is not merely a single firm rather a network of firms, enabling raw material transformation from starting to the end point or finished good to the end user. Therefore, we hypothesize that:

H1: The supply chain information management places a significant impact on the financial performance.

H2: The supply chain information infrastructure places a significant impact on the financial performance.

According to a report, the communication technology and global information system of manufacturing industries has experienced an increased momentum (MIDA, 2017). Using myopic perspective for selecting strategic partners can create various obstacles for many organization in IS design and system integration (Wei, Zhou, \& Lu, 2015). There are many cases in the literature which emphasized that customers and suppliers tend to establish and maintain new relationships based on the ISI foundation. Sundram et al. (2016) suggested that reaching for an outstanding competitive position is the common objective which is also evident from the obtained results. For instance, a telecommunication firm is well informed about the complications and weaknesses in current ISI, which resulted in the management's decision of gaining more development before putting in efforts in the retail business of electricity (Reiss, Xiong, \& Strobel, 2017). The aim of this decision is to reduce higher risk for a firm. Therefore, it is hypothesized that:

H3: The supply chain integration places a significant impact on the financial performance.

Several researchers (Yu et al., 2015) have practically and academically emphasized the SCI's impact. The higher integration brings improvement in firm performance, is the perspective which provides theoretical foundation for the supply chain integration (SCI). The performance studies can be classified into three groups, on the basis of SCI, these are: relationship between external SCI and performance, both SCI types and performance, and between performance and internal supply chain integration. In addition, integrating critical success factors of firm performance provides the basis for a wider organizational performance perspective for the manufacturing sector. Resultantly, operational efficiency measures may help to integrate employees, customers, product-related performance or market aspects to provide a comprehensive and accurate scale for the effectiveness of manufacturing firm financial performance:

H4: The supply chain information management places a significant impact on the supply chain integration. 
H5: The supply chain information infrastructure places a significant impact on the supply chain integration.

The previous hypothesis creates a linkage between SCI, financial performance and SC information practices. Therefore, the rationale for present study hypotheses is that Supply chain information practices influence SCI, which tends to influence performance of manufacturing firms. According to the literature, supply chain ISI and supply chain information management have their direct impact on the financial performance ( $\mathrm{H} 3 \& \mathrm{H} 4)$, however, the supply chain information practices may pose indirect effects via SCI. Therefore, it is suggested that financial performance is influenced by both SC information infrastructure and supply chain information management depending on the size of their impact on SCI. Such indirect effects can somehow be credited to the timely and quality information sharing, because SC information practices facilitate in transforming an individual firm into the integrated business processes.

For instance, Sundram et al. (2016) suggested that manufacturing firms tend to share inventory and order related information among its suppliers, in order to facilitate them through timely development of high-quality services and materials. Supply chain integration involves information sharing and communication about production scheduling and data inventory and collaboration with suppliers, resulting in the reduction of upstream complexity(Darley \& Luethge, 2019), in addition, the bull-whip effect can be reduced by firms' collaboration and information sharing about the demand forecasts and production plans among firms and suppliers. Previous studies suggest that SC information practices can result in the improvement of manufacturing firm performance, by the indirect influence of SCI. Thus, it is hypothesized that:

H6: The supply chain integration mediates the relationship between supply chain information management and the financial performance.

H7: The supply chain integration mediates the relationship between supply chain information infrastructure and the financial performance.

\section{Methodology}

In this study, the main concern is the survey response rate, since it verifies that the information collection through questionnaire is valid to perform data analysis. According to scholar, response rate is that proportion of respondents which took part in survey as part of the research's determined sample size. For data collection, questionnaires were distributed to 239 targeted respondents and out of which 137 were received back. Thus, a 57.32\% response rate was obtained which is sufficient for data analysis, as the minimum acceptable response rate suggested by Dikko (2016) is $30 \%$. The statistical package for Social Sciences
(SPSS) v. 22 and the Smart PLS software were used as main statistical analysis tools for the data analysis. In present study, SPSS acts as a powerful statistical software to perform multiple statistical procedures, including data entry, preliminary data cleaning process, descriptive analysis, obtaining t-statistics for non-response bias detection, measuring internal consistency, detection and treatment for missing data and outliers, and checking multivariate assumptions, such as, multicollinearity, linearity, normality, homoscedasticity. To determine structural and measurement model, a Smart PLS 2.0 was employed which was developed by Ringle, Wende, and Becker (2015)

The study items used for developing this study were being classified into three constructs, namely, supply chain integration, financial performance and supply chain information practices, where supply chain information practices were sub-divided into information system infrastructure and information management. All items of these dimensions were incorporated after reviewing the previous studies and literature of SCM. Likert scale was employed for estimating the items responses, which range from 1-7, where 1 represents extremely strongly disagree and 7 represents extremely strongly agree. Afterwards, the Cronbach alpha test was performed to measure scale reliability. In addition, supply chain information management is estimated through a 7-itemed scale, which was developed for measuring information management's usefulness for the organization. The items include: scheduling among marketers, suppliers, manufacturers, and distributors and joint production planning; accurate information availability for firm in decision-making process, and timely dissemination of information throughout the SC. The Cronbach's $\alpha$ or internal consistency value came out to be 0.907 .

A seven-itemed scale was also used to measure supply chain ISI. This scale is designed for measuring the IS link's capability in organizational activities. This scale includes following items: using electronic data exchange for daily operations, use of automated data obtaining system, e.g. RFID tags and barcode, and employing flexible manufacturing system across the manufacturing process. For this scale, the Cronbach's $\alpha$ value came out to be 0.911 . For measuring supply chain integration (SCI), a seven-itemed scale was employed, which was designed to determine the extent of organization's communication among suppliers and customers. The scale items include, more frequent connection among each other, firms develop compatibility among IS and communication, and extending SC beyond supplier and customers. Thus, the Cronbach $\alpha$ value came out to be 0.898 . Moreover, a seven-itemed scale was also used for estimating financial performance. This scale was developed to assess the abilities of an organization to conduct manufacturing activities for greater performance achievement(Hafeez, Basheer, \& Rafique, 2018). These items may involve order fulfillment speed, meeting delivery at the due date, and manufacturing throughput time. The Cronbach's $\alpha$ or internal consistency for this scale is obtained as 0.919 . 


\section{Results}

The structural model in current research was employed to test the proposed set of hypotheses. Jaafar, Noor, and Rasoolimanesh (2015) suggested that SEM enables to simultaneously determine the interrelated dependence relationships. It is obligatory for the researchers to substantially justify the reasoning to adopt PLS path modeling. In case of present research, PLS-SEM was chosen after several considerations to adapt to the current research needs and specific context. These considerations are explained as follows:

Firstly, the research model for this study was complex, since it had significant indicator variables and paths. According to Jaafar et al. (2015), a complex model refers to a larger model having several number (50 or more) of latent indicators. Under such model complexity, employing PLSSEM was considered to be the most suitable technique because PLS-SEM is a highly competent technique for estimating the complex relationships (Jaafar et al., 2015; Wamba et al., 2017). Moreover, the PLS is a robust technique for complex model handling, without creating any estimation problems (Hair, Hult, Ringle, \& Sarstedt, 2016;
Jaafar et al., 2015; Wamba et al., 2017), with limited features of information procedure (Castaño, Méndez, \& Galindo, 2016). Furthermore, estimating complex models using PLS reduces the model complexity and provide greater theoretical parsimony (Jaafar et al., 2015). Secondly, employing PLS can effectively handle small sample size issue, due to its less strict sample size requirements and residual distributions, contrary to other SEM techniques, for instance AMOS and LISREL. For present study, incorporating PLS for 134 useable questionnaires has provided higher statistical power to this research to address this complex model with small sample size (Henseler, Ringle, \& Sarstedt, 2015).

Henseler et al. (2015) found goodness-of-fit index to be unsuitable to confirm model validation. Therefore, following the Henseler et al. (2015) recommendation, the current research employed a two-step procedure for evaluating the PLS-SEM paths. These steps involve, 1) measurement model assessment and 2) structural model assessment. Individual item reliability, internal consistency reliability, discriminant and convergent validity helps in determining the measurement model (Hair et al., 2016; Hair, Hult, Ringle, \& Thiele, 2017; Henseler et al., 2015), as shown by Figure 1.

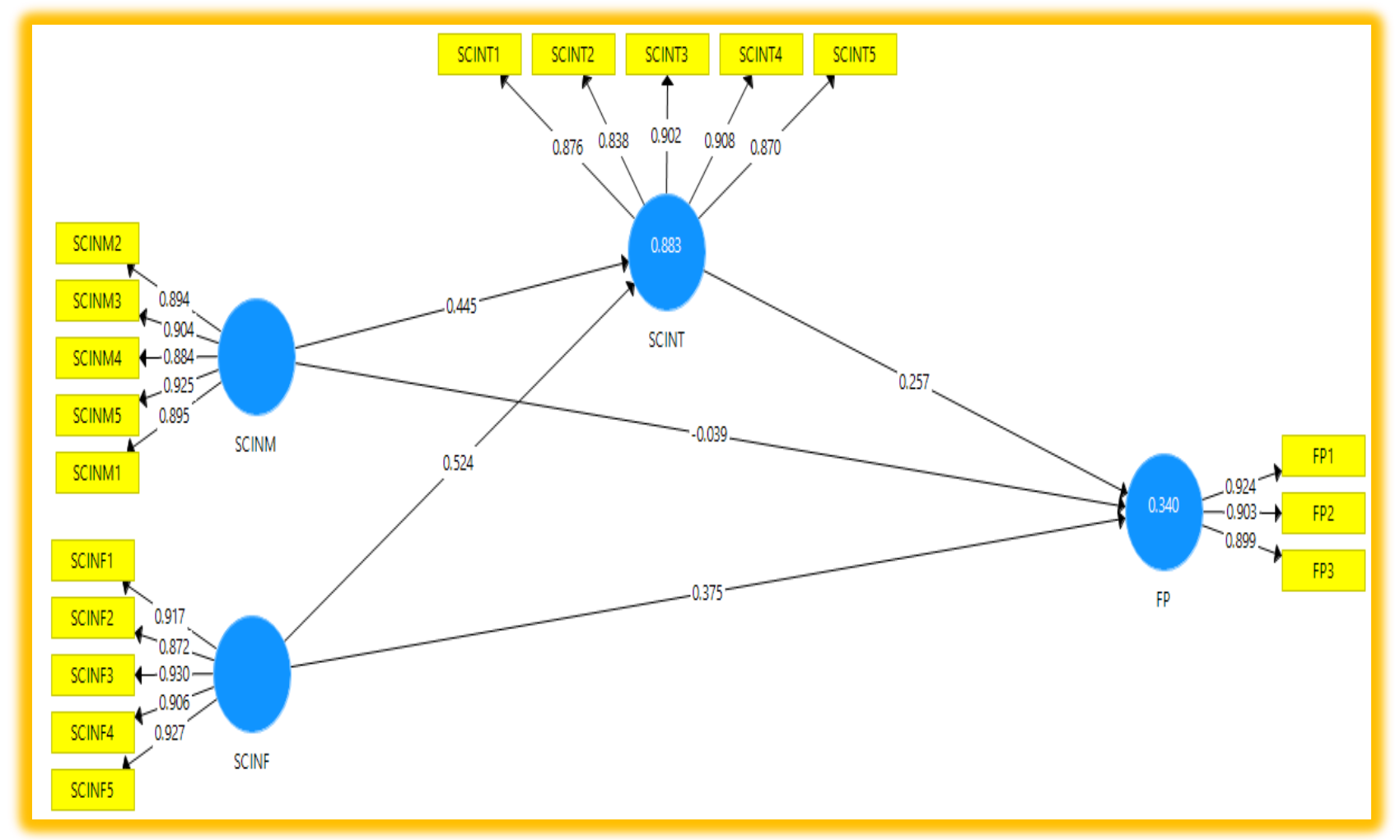

Figure 1: Measurement Model

According to Hair, Sarstedt, and Hopkins (2014), individual item reliability shows the reliability of each item. It is generally determined by observing each construct's individual outer loadings (Hair et al., 2014). Davcik and Sharma (2016) suggested that various weak outer loadings cases are available in the social science literature. Items which have lower outer loadings i.e. 0.40-0.70, must not be included into the model, to increase composite reliability and AVE (Table 1). 
Table 1: Outer Loadings

\begin{tabular}{|l|r|r|r|r|}
\hline & \multicolumn{1}{|l|}{ FP } & \multicolumn{1}{l|}{ SCINF } & \multicolumn{1}{l|}{ SCINM } & \multicolumn{1}{l|}{ SCINT } \\
\hline FP1 & 0.924 & & & \\
\hline FP2 & 0.903 & & & \\
\hline FP3 & 0.899 & & & \\
\hline SCINF1 & & 0.917 & & \\
\hline SCINF2 & & 0.872 & & \\
\hline SCINF3 & & 0.930 & & \\
\hline SCINF4 & & 0.906 & & \\
\hline SCINF5 & & 0.927 & & \\
\hline SCINM2 & & & 0.894 & \\
\hline SCINM3 & & & 0.904 & \\
\hline SCINM4 & & & 0.884 & \\
\hline SCINM5 & & & 0.925 & \\
\hline SCINT1 & & & & 0.876 \\
\hline SCINT2 & & & & 0.838 \\
\hline SCINT3 & & & & 0.902 \\
\hline SCINT4 & & & & 0.908 \\
\hline SCINT5 & & & & 0.870 \\
\hline SCINM1 & & & 0.895 & \\
\hline
\end{tabular}

Internal consistency reliability is the extent that a particular scales' items measure the same concept. Composite reliability and Cronbach alpha coefficient are the commonest estimators to determine an instrument's internal consistency reliability. Therefore, to determine the adapted measures' internal consistency reliability, the present study employed the composite reliability measure. The present study did not choose Cronbach alpha because; 1) in comparison to Cronbach alpha, the composite reliability gives less biased estimates; and assume equal weights for all indicators(Amaro \& Duarte, 2016; Castaño et al., 2016); 2) Cronbach alpha does not appropriately estimate scale reliability, it either overestimates or underestimates it, whereas, composite reliability considers and ensures that each indicator has different loadings. Composite reliability, thus recognizes all items' individual loadings and also determines each items contribution. However, the convergent validity shows that to what extent the items represent the construct's which they are intended to represent (Hair et al., 2016). Therefore, the current research determined convergent validity as suggested by Tzempelikos and Gounaris (2017) i.e. analyzing each latent construct's average variance extracted (AVE) values(Table 2).

Hair et al. (2014) defined discriminant validity as to what extent there is an empirical distinction among a particular construct and other latent constructs. Thus, an AVE Tzempelikos and Gounaris (2017) and cross loadings were used for determining the discriminant validity for this research. Discriminant validity is achieved when the square roots of AVE exhibit larger values from the correlation of other latent variables, as suggested by Tzempelikos and Gounaris (2017). Table 3 presents the AVE square root values which were found to be exceeded from the correlations between latent constructs, thus discriminant validity is established.
Table 2: Reliability

\begin{tabular}{|l|l|l|l|l|}
\hline & $\begin{array}{c}\text { Cronbach' } \\
\text { s Alpha }\end{array}$ & \multicolumn{1}{|c|}{ rho_A } & CR & (AVE) \\
\hline FP & 0.895 & 0.900 & 0.934 & 0.826 \\
\hline SCINF & 0.948 & 0.950 & 0.960 & 0.829 \\
\hline SCINM & 0.942 & 0.943 & 0.955 & 0.811 \\
\hline SCINT & 0.926 & 0.927 & 0.944 & 0.773 \\
\hline
\end{tabular}

Table 3: Validity

\begin{tabular}{|l|l|l|l|l|}
\hline & \multicolumn{1}{|c|}{ FP } & \multicolumn{1}{c|}{ SCINF } & SCINM & SCINT \\
\hline FP & 0.909 & & & \\
\hline SCINF & 0.876 & 0.911 & & \\
\hline SCINM & 0.825 & 0.883 & 0.901 & \\
\hline SCINT & 0.765 & 0.816 & 0.900 & 0.879 \\
\hline
\end{tabular}

In order to determine the path coefficients' significance, the bootstrapping procedure, with 5000 bootstrap samples was applied in present study for treating 134 cases as recommended by Henseler et al. (2015) and Hair et al. (2014). Since PLS-SEM assume non-normality of data, therefore it is necessary to apply bootstrapping in PLS (Hair et al., 2014). According to Henseler et al. (2015), bootstrapping technique provides reasonable estimates of standard error. Furthermore, path coefficient explains the relational strength among hypothesized relationships and independent and dependent variables (Table 4).

Table 4: Direct Relations

\begin{tabular}{|l|c|c|c|c|c|}
\hline & $(\mathbf{O})$ & $(\mathbf{M})$ & $\begin{array}{c}\text { (STD } \\
\text { EV) }\end{array}$ & $\begin{array}{c}\mathbf{T} \\
\text { Stati- } \\
\text { stics }\end{array}$ & $\begin{array}{c}\mathbf{P} \\
\text { Values }\end{array}$ \\
\hline SCINF -> FP & 0.509 & 0.520 & 0.129 & 3.951 & $\mathbf{0 . 0 0 0}$ \\
\hline SCINF -> SCINT & 0.524 & 0.527 & 0.086 & 6.103 & $\mathbf{0 . 0 0 0}$ \\
\hline SCINM -> FP & 0.075 & 0.068 & 0.149 & 0.507 & $\mathbf{0 . 3 0 6}$ \\
\hline SCINM -> SCINT & 0.445 & 0.442 & 0.087 & 5.092 & $\mathbf{0 . 0 0 0}$ \\
\hline SCINT -> FP & 0.257 & 0.249 & 0.176 & 1.458 & $\mathbf{0 . 0 7 2}$ \\
\hline
\end{tabular}

For structural model assessment, another criterion in PLS-SEM is R-squared value or coefficient of determination (Hair et al., 2014; Henseler et al., 2015). The coefficient of determination $\left(\mathrm{R}^{2}\right)$ shows the proportional variation in dependent variable which can be predictable from independent variables (Figure 2 and Table 5).

Table 5: Mediation
\begin{tabular}{|l|c|c|c|c|c|}
\hline & $(0)$ & $(M)$ & $\begin{array}{c}(\text { STD } \\
\text { EV) }\end{array}$ & $\begin{array}{c}\text { T } \\
\text { Stati- } \\
\text { stics }\end{array}$ & $\begin{array}{c}\mathbf{P} \\
\text { Values }\end{array}$ \\
\hline $\begin{array}{l}\text { SCINF }->\text { SCINT } \\
->\text { FP }\end{array}$ & 0.134 & 0.129 & 0.095 & 1.415 & $\mathbf{0 . 0 7 9}$ \\
\hline $\begin{array}{l}\text { SCINM }->\text { SCINT } \\
\rightarrow \text { FP }\end{array}$ & 0.114 & 0.112 & 0.084 & 1.366 & $\mathbf{0 . 0 8 6}$ \\
\hline
\end{tabular}

The greater the value of $\mathrm{R}^{2}$ the greater the explanatory power and predictive accuracy of predicting variables (Hair et al., 2014). The minimum acceptable value for $\mathrm{R}^{2}$ is 0.10 . However, in view ofHenseler et al. (2015), the $\mathrm{R}^{2}$ with value 0.67 shows substantial predictive accuracy, 0.33 shows moderate predictive accuracy and 0.19 shows weak predictive accuracy, with $0.12-0.30$ values for path coefficients (Table 6). 


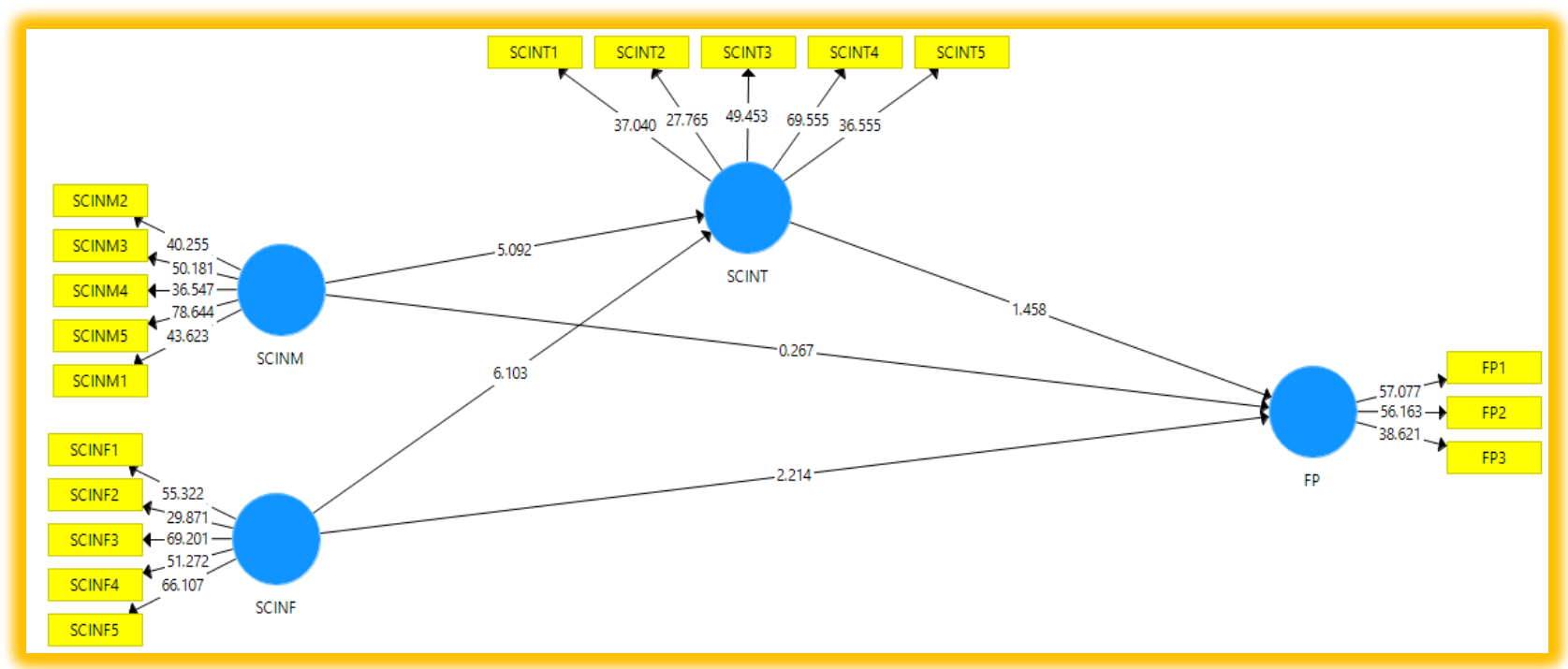

Figure 2: Structural Model

Table 6: R-Square

\begin{tabular}{|c|c|}
\hline & R Square \\
\hline FP & 0.340 \\
\hline SCINT & 0.883 \\
\hline
\end{tabular}

Afterwards, a cross-validated redundancy measure $\left(Q^{2}\right)$ Henseler et al. (2015)was used for checking the predictive relevance of the model. A research model with greater than 0 value for $\mathrm{Q}^{2}$ statistic shows that the model has predictive relevance, whereas, if the obtained value for $\mathrm{Q}^{2}$ statistic comes out to be below zero, then it indicates no predictive relevance (Ringle et al., 2015).

The results of blindfolding procedure are presented in Figure 3 and Table 7 . The table shows that for all endogenous constructs greater than 0 values were obtained for $\mathrm{Q}^{2}$, which confirm that model has predictive relevance.

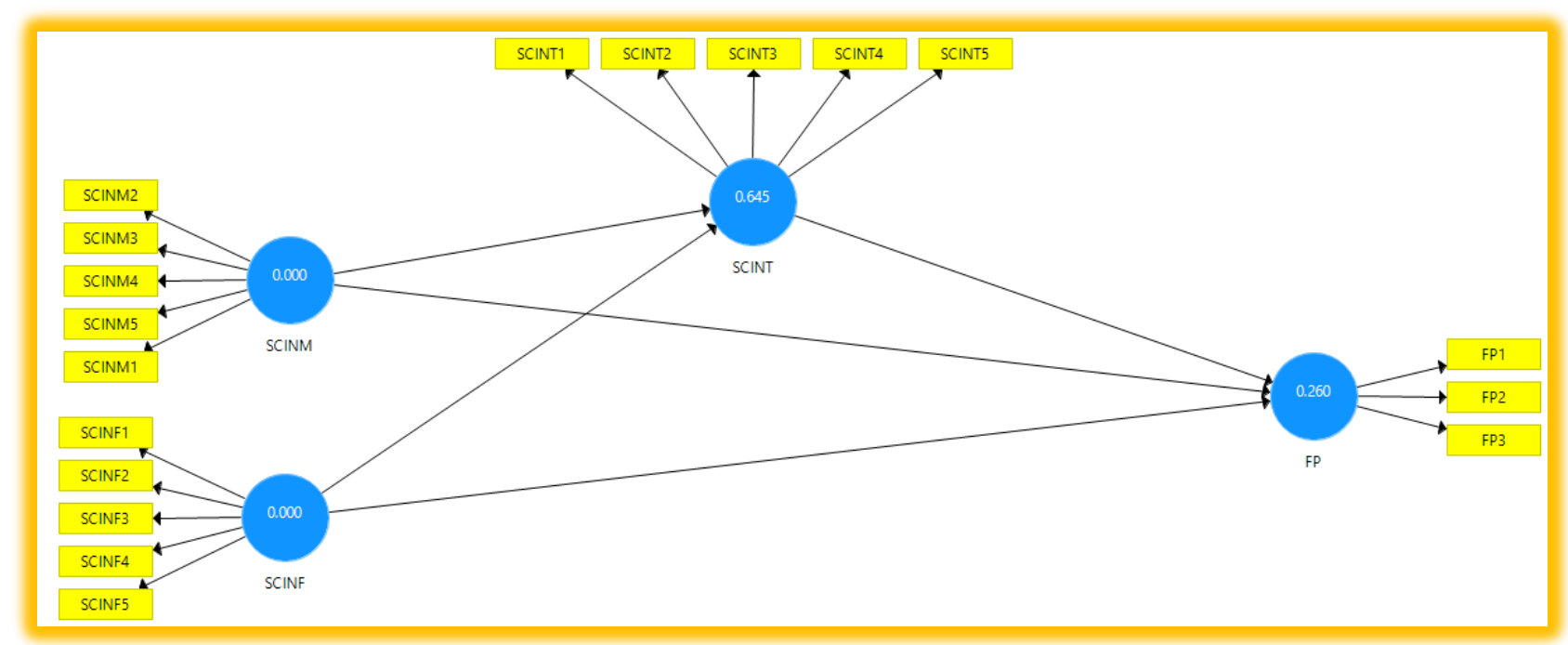

Figure 3: Blindfolding's

Table 7: Predictive Relevance

\begin{tabular}{|l|r|r|r|}
\hline & \multicolumn{1}{|c|}{ SSO } & \multicolumn{1}{c|}{ SSE } & $\mathbf{Q}^{2}$ (=1-SSE/SSO) \\
\hline FP & 651.000 & 481.752 & 0.260 \\
\hline SCINF & $1,085.000$ & $1,085.000$ & \\
\hline SCINM & $1,085.000$ & $1,085.000$ & 0.645 \\
\hline SCINT & $1,085.000$ & 385.025 & \\
\hline
\end{tabular}

\section{Conclusion}

A model is presented in this paper to provide understanding of the supply chain integration and supply chain information practices' impact on the manufacturing industries. The supply chain information practices play a 
crucial role in sharing information between the members of SC network. Thus, it is important to develop a comprehensive understanding of the differences and similarities among ISI and information management. It will allow firms to systematically evaluate and carefully choose the information strategy (Fuchs \& Otto, 2015).The empirical findings of this research offer essential and interesting insights about what role SCI, supply chain information and Supply chain ISI play in determining Malaysia's financial performance.

Therefore, several conclusions from theoretical viewpoint can be drawn for SCI and supply chain information practices. Firstly, the current research enables firms to emphasize more on the SCM for processes adjustment, by choosing that system which is appropriate, and which supports the information infrastructure and information management visibility for enhancing the financial performances. In addition, the supply chain ISI aims to capitalize on those technological advancements which has less impact on the environment, and which in turn brings improvement in the supply chain network's level of responsiveness. The findings suggest that in manufacturing industry, supply chain information practices serve to be the significant strategic resources. Although, their contribution in the performance of manufacturing industries depends largely on manufacturing firms' integration in the SC. Putting differently, there must be alignment of such practices to ensure value chain integration along the internal and upstream manufacturing supply chain processes. These findings are in consistent with the ones obtained by other researches, such as Banerjee and Mishra (2017).

The success of Malaysian manufacturing industry depends heavily upon supply chain information practices implementation, since the Malaysian manufacturing industry is faced with Industry 4.0 or the fourth Industrial revolution. The supply chain information practices include supply chain ISI and supply chain information management. Therefore, these findings can be used in this study to create new ideas and plans for future researches and managers can also gain important knowledge that in what ways supply chain integration and supply chain information practices could effectively influence the financial performance. Considering such factors, the Ministry of Communication and Multimedia has designed various policies in Malaysia, with a purpose of encouraging firms, particularly manufacturing firms, to make more investment for integrating technology and information system to improve business operations. Moreover, firms are allowed to take Accelerated Capital Allowance (ACA), which offer initial and annual allowance of 20 and 40 percent respectively, to finance the expenses that are incurred on IT assets.

\section{Implications}

The theoretical gaps addressed in this study are of significant importance, since a little empirical evidence is available regarding system infrastructure and supply chain information management's effectiveness(Hameed, Basheer, \& Anwar, 2018), having SCI's influence on financial performance. The study also offers implication for the supply chain members i.e. to connect with the information network for support provision to the managers to make better decisions regarding system infrastructure and information management. In addition, it also facilitates in identifying and retrieving information among various members of SC network.

Furthermore, in order to reverberate this potential throughout the SC partners, system theory plays the most important role through promoting integration. Thus, system infrastructure and information management have critical role in the success of integration across and within the SC.

\section{References}

Amaro, S., \& Duarte, P. (2016). Modelling formative second order constructs in PLS. The $15^{\text {th }}$ European Conference on Research Methodology for Business and Management Studies. Kingston Business School, Kingston University London, UK.

Andoh-Baidoo, F. K. (2016). Organizational information and communication technologies for development. Information Technology for Development, 22(2), 193204.

Bahrin, A. S., Abdul Munir, Z. B., \& Zolait, A. H. (2018). The effect of supply chain information management and information system infrastructure: The mediating role of supply chain integration towards manufacturing performance in Malaysia. Journal of Enterprise Information Management, 31(5), 751-770.

Banerjee, M., \& Mishra, M. (2017). Retail supply chain management practices in India: A business intelligence perspective. Journal of Retailing and Consumer Services, 34, 248-259.

Basheer, M. F., Hafeez, M. H., Hassan, S. G., \& Haroon, U. (2018). Exploring the role of TQM and supply chain practices for firm supply performance in the presence of organizational learning capabilities: A case of textile firms in Pakistan. Paradigms, 12(2), 172-178.

Basheer, M., Siam, M., Awn, A., \& Hassan, S. (2019). Exploring the role of TQM and supply chain practices for firm supply performance in the presence of information technology capabilities and supply chain technology adoption: A case of textile firms in Pakistan. Uncertain Supply Chain Management, 7(2), 275-288.

Bendoly, E., \& Chao, R. O. (2016). How excessive stage time reduction in NPD negatively impacts market value. Production and Operations Management, 25(5), 812-832.

Castaño, M. S., Méndez, M. T., \& Galindo, M.-Á. (2016). Innovation, internationalization and business-growth expectations among entrepreneurs in the services sector. Journal of Business Research, 69(5), 1690-1695. 
Ceric, A. (2016). Analysis of interactions between IT and organisational resources in a manufacturing organisation using cross-impact analysis. Journal of Enterprise Information Management, 29(4), 589-611.

Darley, W. K., \& Luethge, D. J. (2019). Service value and retention: Does gender matter? Journal of Retailing and Consumer Services, 48, 178-185.

Davcik, N. S., \& Sharma, P. (2016). Marketing resources, performance, and competitive advantage: A review and future research directions. Journal of Business Research, 69(12), 5547-5552.

Dikko, M. (2016). Establishing construct validity and reliability: Pilot testing of a qualitative interview for research in Takaful (Islamic insurance). The Qualitative Report, 21(3), 521-528.

Fuchs, C., \& Otto, A. (2015). Value of IT in supply chain planning. Journal of Enterprise Information Management, 28(1), 77-92.

Gorane, S., \& Kant, R. (2017). Supply chain practices and organizational performance: An empirical investigation of Indian manufacturing organizations. The International Journal of Logistics Management, 28(1), 75-101.

Govindana, K., \& Soleimanib, H. (2017). A review of reverse logistics and closed-loop supply chains: A Journal of Cleaner Production focus', Journal of Cleaner Production, 142(1), 371-384.

Hafeez, M. H., Basheer, M. F., Rafique, M., \& Siddiqui, S. H. (2018). Exploring the links between TQM practices, business innovativeness and firm performance: An emerging market perspective. Pakistan Journal of Social Sciences, $\quad 38(2)$ Available at: https://www.bzu.edu.pk/PJSS/Vol.\%2038,\%20No.\%202, \%202018/PJSS-Vol38-No2-11.pdf

Hair Jr., J. F., Hult, G. T. M., Ringle, C., \& Sarstedt, M. (2016). A primer on partial least squares structural equation modeling (PLS-SEM). (2nd ed.). Thousand Oaks, CA: Sage Publications.

Hair Jr., J. F., Hult, G. T. M., Ringle, C. M., \& Thiele, K. O. (2017). Mirror, mirror on the wall: A comparative evaluation of composite-based structural equation modeling methods. Journal of the Academy of Marketing Science, 45(5), 616-632.

Hair Jr., J. F., Sarstedt, M., Hopkins, L., \& Kuppelwieser, V. G. (2014). Partial least squares structural equation modeling (PLS-SEM) An emerging tool in business research. European Business Review, 26(2), 106-121.

Hameed, W. U., Basheer, M. F., Iqbal, J., Anwar, A., \& Ahmad, H. K. (2018). Determinants of firm's open innovation performance and the role of $R \& D$ department: An empirical evidence from Malaysian SME's. Journal of Global Entrepreneurship Research, 8(1), Article number: 29(2018). Available at: https://journal-

jger.springeropen.com/articles/10.1186/s40497-0180112-8

Hameed, W. U., Nawaz, M., Basheer, M. F., \& Waseem, M. (2019). The Effect of Amanah Ikhtiar Malaysia (AIM) on microenterprise success in Sabah State Malaysia. Dialogue (1819-6462), 14(2). Available at: http://www.qurtuba.edu.pk/thedialogue/The\%20Dialogu e/14_2/19-Waseem.pdf

Henseler, J., Ringle, C. M., \& Sarstedt, M. (2015). A new criterion for assessing discriminant validity in variancebased structural equation modeling. Journal of the Academy of Marketing Science, 43(1), 115-135.

Jaafar, M., Noor, S. M., \& Rasoolimanesh, S. M. (2015). Perception of young local residents toward sustainable conservation programmes: A case study of the Lenggong World Cultural Heritage Site. Tourism Management, 48, 154-163.

Jagani, S., Wallace, S., \& Kunnathur, A. (2016). A research framework for business sustainability using information exchange: A firm centric perspective. Twenty-second Americas Conference on Information Systems, San Diego, 2016. Available at: https://pdfs.semanticscholar.org/7e92/2bcb16b0569b2b6 708d0e2cd8c69215b3acc.pdf

Kembro, J., Näslund, D., \& Olhager, J. (2017). Information sharing across multiple supply chain tiers: A Delphi study on antecedents. International Journal of Production Economics, 193, 77-86.

Lu, M., Xie, R., Chen, P., Zou, Y. \& Tang, J. (2019). Green transportation and logistics performance: An improved composite index. Sustaiability, 11(2976), 1-17.

Messina, D., Barros, A. C., \& Lucas, A. (2018). How much visibility has a company over its supply chain? A diagnostic metric to assess supply chain visibility. 22nd Cambridge International Manufacturing Symposium. University of Cambridge, Cambridge, England https://doi.org/10.17863/CAM.31715

Mukiibi, H. Y. (2018). Improving supply-chain information flow: A case study of Uganda Health Marketing Group (UHMG). Master Research Report, Makerere University, Kampala, Uganda

Paul, J., Parthasarathy, S., \& Gupta, P. (2017). Exporting challenges of SMEs: A review and future research agenda. Journal of World Business, 52(3), 327-342.

Ramanathan, U., Subramanian, N., \& Gunasekaran, A. (2018). Closed-loop supply chain collaboration: A study of the packaging industry. BAM2018: British Academy of Management Conference, Bristol Business School, University of the West of England, Bristol, 4-6 September 2018

Reiss, C. W., Xiong, Y., \& Strobel, S. A. (2017). Structural basis for ligand binding to the guanidine-I riboswitch. Structure, 25(1), 195-202.

Ringle, C. M., Wende, S., \& Becker, J.-M. (2015). SmartPLS 3. Bönningstedt: SmartPLS.

Salmela, E., \& Huiskonen, J. (2019). Co-innovation toolbox for demand-supply chain synchronisation. International Journal of Operations \& Production Management, 39(4), 573-593.

Sigalas, C., \& Papadakis, V. M. (2018). Empirical investigation of relationship patterns between 
competitive advantage and superior performance. Journal of Strategy and Management, 11(1), 81-111.

Sundram, V., Chandran, V., Atikah, S., Rohani, M., Nazura, M., Akmal, A., \& Krishnasamy, T. (2016). Research methodology: Tools, methods and techniques. MLSCA, Selangor, Malaysia.

Thatte, A., \& Agrawal, V. (2017). Exploring supply chain responsiveness effects on competitive advantage of a firm. Quarterly Review of Business Disciplines, 4(3), 211-228.

Tzempelikos, N., \& Gounaris, S. (2017). A conceptual and empirical examination of key account management orientation and its implications-the role of trust The Customer is NOT Always Right? Developments in Marketing Science: Proceedings of the Academy of Marketing Science: Springer, Cham

Walker, D. H. (2016). Reflecting on 10 years of focus on innovation, organisational learning and knowledge management literature in a construction project management context. Construction Innovation, 16(2), 114-126.

Wamba, S. F., Gunasekaran, A., Akter, S., Ren, S. J.-f., Dubey, R., \& Childe, S. J. (2017). Big data analytics and firm performance: Effects of dynamic capabilities. Journal of Business Research, 70, 356-365.

Wei, X., Gao, B., Wang, P., Zhou, H., \& Lu, J. (2015). Pollution characteristics and health risk assessment of heavy metals in street dusts from different functional areas in Beijing, China. Ecotoxicology and Environmental Safety, 112, 186-192.

Yu, Y., Xiong, W., \& Cao, Y. (2015). A conceptual model of supply chain risk mitigation: The role of supply chain integration and organizational risk propensity. Journal of Coastal Research, 73(sp1), 95-99. 